\title{
The Usefulness of Using Generalizing Words for Teaching Summary Writing
}

\author{
Fiona Kwai-peng SIU \\ City University of Hong Kong, Hong Kong
}

\begin{abstract}
Different approaches have been used to teach EFL students summary writing, including a genrebased approach (Chen \& Su, 2012), implementing key words and question generation (Chou, 2012), and automatic scaffolding and concept mapping (Yang, 2015). This study aims to explore the effectiveness of another approach - one that might be more appropriate to the participants in this study - using generalizing words (such as "solutions" and "difficulty"). Such words were intended to help students visualize the macrostructure of a passage. In the first phase of this approach, a template containing generalizing words was provided to students to guide them in finding the main points of the passage. In the second phase, students were expected to generate generalizing words themselves. Students were also taught how to achieve paragraph coherence by making use of the generalizing words produced. The experimental group scored slightly higher marks in three measures (i.e., Idea Flow, Paraphrasing Techniques and Total Score) than did the control group in the end-of-course summary writing examination, though the differences were not significant at the 95\% confidence level. Questionnaire findings revealed the difficulties perceived by participants in completing a summary task and the ways in which this approach had helped them.
\end{abstract}

Index Terms - teaching summary writing, genre, paragraph coherence, generalizing words, L2 writing

\section{INTRODUCTION}

Summary writing, although constituting an important academic skill for university students, has been found to be a difficult task for L2 learners (Alfassi, 2004; Fischer, 2003; Friend, 2001; Kintsch, 1998; Yang, 2014; Yang 2015; Yang 2016). The successful production of a good summary requires such complex cognitive skills as understanding the grammatical and semantic relationship between words in a sentence, grasping the main idea of a paragraph, and subsequently selecting the most important information based on the instructions of a summary task. Esmaeili (2002) and Plakans (2009) suggested that students' difficulty in reading comprehension might hinder them from incorporating the source materials into their summary writing. In the process of selecting the main points and relevant supporting details, students' knowledge of the text structure also plays an important role. At the later stage of attempting to produce a wellorganized summary, a student faces even more various challenges, such as using effective paraphrasing skills and allotting ideas into hierarchy from generality to specificity. Words that are more general (for example, such words as headings) can sometimes be found in a source passage, but it is not uncommon that such general words, to which specific details are subsumed, have to be generated by the summary writers themselves. Such general words, subsuming more specific ideas, are termed generalizing words in this present study. (See the definition in the following paragraph.) Nevertheless, the formation of generalizing words may pose a great difficulty for students possessing a relatively low level of English proficiency and a poor ability of abstraction, although students with high skills in these two regards may find it easier to identify the hierarchical relationship between ideas along the scale from generality to specificity.

A generalizing word is defined as a word or phrase that gives a general description of the subject of a section of a piece of writing. A generalizing word performs similar functions as a heading/sub-heading, but it is not customary to include a heading/sub-heading in a piece of summary writing. Therefore, there seemed to be a need for the present researcher to create the term generalizing words in order to convey to students the message that such words should be incorporated into a summary to improve the organization of the summary. Furthermore, a heading/sub-heading appearing in the original passage may be too general to function well as effective transitional words between sets of important details; in such a case, generalizing words - which can be considered to occur between two ending points along a continuum of specificity (top end: headings/sub-headings; bottom end: specific details) - would become necessary and useful. The differences among the terms headings, generalizing words and specific details are illustrated in the following examples taken from the outline template produced for the source passage "Death: a discovery approach"(Appendix A):

CORRESPONDING HEADING APPEARING IN THE SOURCE PASSAGE:

WAYS TO VIEW DEATH

GENERALIZING WORDS:

Justification for the course; aim of the course; features of the course

SPECIFIC DETAILS:

- Reason 1: Death is not discussed openly in Chinese communities. 
- Reason 2: We are confronted by images of death, often with very violent and graphic images

- To inspire students to examine fundamental questions about death.

- Multidisciplinary

- Department of Applied Social Studies

- We need to include a study of ethics, religion and humanism when talking about death. Subjects like euthanasia and living wills are becoming more important in contemporary societies.

The term generalizing words is derived from a conception of generalization. According to Halliday and Matthiessen (1999), generalization relates to the "the development of extended taxonomic hierarchies" (p.615). For example, the term jobs is "a superordinate term in a taxonomic relationship of hyponymy (kind of) to librarian and museum curator" (Hood, 2008, p.357). However, the ability to generate generalizing words involves an ability that goes beyond the ability of classification (e.g., librarian as an instance of jobs). To produce generalizing words, the ability of abstraction is required. The example provided by Hood (2008) illustrates that kind of abstraction ability: the relationship between position and where you stand is an abstraction rather than a classification.

Previous research into summary writing focuses mainly on improving students' ability to identify the main points and supporting details rather than the way to improve the organization of a summary. The genre-based approach is considered to be effective in helping students to improve the content and the organization of a summary (Chen \& Su, 2012). They investigated the effectiveness of teaching forty-one university students in Taiwan the rhetorical structure of a narrative source text -- namely, the setting, initial events, internal responses, attempts, consequences, and reactions (Stein \& Glenn, 1979). Another approach involves implementing key words (Chou, 2012; Ercan \& Cicekli, 2007; Fritz et al. 2006; Sagarra \& Alba, 2006; Wang, Thomas, \& Quellette, 1992) and generating questions (Chou, 2012; De Fina, 1992; Silver \& Matsuda, 2002). Chou (2012) examined the summary writing of 111 EFL Taiwanese university secondyear students working in the genre of narration. His subjects were required to generate five out of the six journalistic questions (i.e., the $5 \mathrm{~W} 1 \mathrm{H}$ [who, what, where, why, when, and how] and to identify three keywords from each of the eight assigned readings taken from magazines, newspapers and the Internet). Chou (2012) concluded that the approach of implementation of keywords and question generation was effective in improving the subjects' scores, which covered four equally weighted subscales: content relevance, coherence, appropriate use of vocab, as well as grammar and spelling. Yet, Chou (2002) did not examine whether the sub-score of coherence had improved.

The third approach focuses on the use of automatic scaffolding and concept mapping (Wu, Hwang, Milrad, Ke, \& Huang, 2012; Yang, 2015; Yang 2016). A concept map consists of three levels: the first level involves the central idea in the title; the second level involves the main idea in each paragraph; and the third level involves supporting ideas in each paragraph. Nodes (meaning "main ideas") and links representing the associations between the main ideas are provided in the concept maps. Yang (2015) concluded that automatic scaffolding - that is, the timely feedback students received from the computerized concept maps - allowed students to adjust the words they extracted from a source passage before starting to write the full summary, thus contributing to the overall higher scores than students in the control group who used only paper-version concept maps. The present study did not use the same three levels used by Yang (2015); rather, the skill of creating generalizing words constitutes the second-level of the three-level outline template. As can be seen in the template in Appendix A, headings constitute the first level, corresponding generalizing words the second, and specific details the third level.

In essence, the present study aims to fill the gap not fully investigated in previous studies by examining how using generalizing words would enhance students' grasp of the relationship between ideas along the hierarch from generality to specificity, thereby probably contributing to the production of a well-organized summary.

\section{RESEARCH QUESTIONS}

1. Can the use of generalizing words improve students' summary writing performance?

2. Do students receiving the summary writing instructions in this present study find the teaching methods and teaching materials useful in helping them to write a good summary?

3. What are students' difficulties in completing a summary task?

\section{Methodology}

The experimental group, taught by the present researcher, consisted of three classes of EAP II students totally 66 Year 1 students, who took the 36-hour course offered by the English Language Centre (ELC) at the City University of Hong Kong in the second semester of 2015-16 school year. Each one of the lesson lasted three hours, and there were twelve lessons in the complete semester. Starting from Lesson 4, roughly half the lesson time was used to teach summary writing, while the other half of the lesson time was used to develop students' writing proficiency, for example, in using noun phrases, and in constructing complex sentence structures.

Summary writing was one of the writing skills to be examined in the end-of-course examinations. Another writing skill to be examined was the writing of a 600 -word argumentative essay incorporating some provided citations. The time allowed in the examination for summary writing was 45 minutes. The reading time allowed to read the two passages and to answer reading comprehension questions was 90 minutes. One of the two passages was also used for the task of writing the summary. 
Both the control and the experimental groups scored Level 3 in the Hong Kong Diploma of Secondary Education (HKDSE) or held equivalent examination results. The HKDSE is the only public examination in the new 3-3-4 education system introduced in Hong Kong secondary schools. Candidates' results are labeled Levels 1, 2, 3, 4 and 5, with Level 1 being the lowest and Level 5 the highest. The candidates scoring at the highest level were awarded a score of $5 * *$. To be eligible for admission to a government-subsidized degree program, the minimum requirement for the subject of English Language was set at Level 3.

A questionnaire (Appendix B) intended to collect the students' views of the use of generalizing words and other teaching materials and skills was administered in class in the last lesson of the course on a voluntary basis and anonymously. The students who were present in the class were given five to ten minutes to complete the questionnaire.

The following scores of the summary writing were compared across the two groups using IBM SPSS Statistics 22:

- The total score, and

- The four components -

a) Content (30\%),

b) Paraphrasing Skills (30\%),

c) Idea Flow (10\%), and

d) Grammatical Control (30\%).

All the markers assigned by the department to score the summary examination scripts underwent a one-hour long marker-training session organized by the Assessment Team before the marking period started. Subsequent to the marking training, markers would collect the examination scripts assigned to them by the General Office, which took care to make sure that markers would not mark the scripts written by students they had actually taught.

THE TREATMENT - SUMMARY-WRITING TEACHING INSTRUCTIONS

Step-by-step explicit instructions were used in this present study. As stated by Hashimoto, Fukuda, \& Hironobu, 2015), such an approach can make a summary manageable.

The following stages were involved in the teaching process:

STAGE 1: (Finding the main points of individual paragraphs)

Two passages were used:

First passage:

1. In each paragraph, students were required to underline the most informative sentence that best reflects the main idea of the paragraph.

2. Suggested sentences showing the main idea and important details of each of the paragraphs were provided to students after they had completed their task. Justifications concerning why the suggested answers constituted the main points; the important details were provided by the teacher after the students were given an opportunity to compare their work with the suggested answers.

Second passage:

Similar steps were followed when using the second passage, but students had to express the main ideas and the important details of each paragraph in their own words rather than by merely copying verbatim from the original passage. Asking students to use their own words to express the main ideas of a passage was intended to call the students' attention to the need to paraphrase sentences taken from the passage.

In addition to providing justifications for the selection of the main points and important details, the teacher also drew the students' attention to how the original sentences had been paraphrased.

STAGE 2: (The introduction of generalizing words to indicate the functions of paragraphs)

Two passages were used:

1. In each paragraph, students were required to underline the most informative sentence that would include the main idea of the paragraph. This step was also used in STAGE 1.

2. A table with generalizing words (e.g., benefits, arguments against) was provided to students. They were required to complete the table by supplying the main points and the important details that would match the given generalizing words. A table with generalizing words served the function of providing the students with an outline of the source passage, which should be useful in helping students see the structure of a text (Hashimoto, Fukuda, \& Okazaki, 2015)

3. After students had completed the aforementioned task, suggested answers (which were displayed in the format of a table containing generalizing words, main points and important details) were provided to students (Appendix A). Explanations were given by the teacher after the students had compared their work with the teacher's suggested answers.

4. Students were asked to write a summary of the entire passage, paying attention to the ways used to link up different parts of the passage by using generalizing words to indicate the macro structure of the summary.

5. A sample summary was provided to students (Appendix C). How generalizing words had been used to improve the organization of the text was explained to students. In addition, the teacher also drew students' attention to how the original sentences were paraphrased.

STAGE 3: (The generation of generalizing words by students)

Two passages were used:

Similar steps as those in Stage 2 were used except that students were required to generate generalizing words rather than being provided with them. 
The control group consisted of EAP II students taught by other ELC teachers. The General Office of the ELC randomly selected 66 scripts from the entire collection of examination papers, thus matching the number of examination scripts from the experimental group. The students in the control group were not taught generalizing words in their process of learning summary writing. The teaching materials provided in the EAP II Student Booklet covered such general skills as recognizing the genre of a passage, recognizing the main ideas of paragraphs, crossing less important details, and using cohesive devices to show relationships of ideas. Further, to the best knowledge of the present researcher, the term generalizing words has not been used in related body of literature.

\section{RESULTS}

\section{Summary-Writing Examination results}

The five examination scores of the two groups are shown in Table 1.

As can be seen in Table 1, three scores out of five awarded to the experimental group were slightly higher than those of the control group, although they were not significantly different at $\mathrm{p} \leq 0.05$ (Total Score: 10.74 versus 10.55; Paraphrasing Skills: 2.61 versus 2.44; Idea flow: 2.85 versus 2.73).

TABLE 1:

THE SCORES OF THE TWO GROUPS AT THE END-OF-COURSE SUMMARY EXAMINATION

\begin{tabular}{llllll}
\hline & Group & $\mathrm{N}$ & mean & Std. Deviation & $\begin{array}{l}\text { Significance } \\
(2 \text {-tailed) }\end{array}$ \\
\hline Content & 1 & 66 & 2.48 & 1.0410 & 0.445 \\
& 2 & 66 & 2.62 & 1.004 & 0.445 \\
Paraphrasing Skills & 1 & 66 & 2.61 & 0.721 & 2.225 \\
Idea flow & 2 & 66 & 2.44 & 0.844 & 2.225 \\
& 1 & 66 & 2.85 & 0.438 & 0.173 \\
Grammar & 2 & 66 & 2.73 & 0.570 & 0.173 \\
\multirow{2}{*}{ Total score } & 1 & 66 & 2.79 & 0.512 & 0.589 \\
& 2 & 66 & 2.83 & 0.450 & 0.589 \\
& 1 & 66 & 10.74 & 1.932 & 0.569 \\
& 2 & 66 & 10.55 & 2.032 & 0.569 \\
\end{tabular}

\section{Questionnaire findings}

The participants' views on the suggested methods of writing a well-organized summary

Table 2 below shows the experimental group's views on the usefulness of the teaching materials studied in class. It was found that the two teaching aids - a template containing generalizing words and the list of main points -- were considered to be useful by an overwhelming majority of respondents.

TABLE 2:

PERCEPTION OF THE USEFULNESS OF THE TEACHING MATERIALS USED IN CLASS

\begin{tabular}{|c|c|c|}
\hline & $\begin{array}{l}\text { Yes } \\
\text { (Percentage) }\end{array}$ & $\begin{array}{l}\text { No } \\
\text { (Percentage) }\end{array}$ \\
\hline $\begin{array}{l}\text { a. Are the templates (i.e., blank tables with headings } \\
\text { provided) given by the teacher to show the macro structure } \\
\text { of the passages useful to you? }\end{array}$ & 94.8 & 5.2 \\
\hline $\begin{array}{l}\text { b. Is the list of main points provided to you (after you have } \\
\text { attempted to find the main points yourself) useful to you? }\end{array}$ & 100 & 0 \\
\hline $\begin{array}{l}\text { c. Are you willing to use the steps* taught in class for your } \\
\text { future summary writing? }\end{array}$ & 100 & 0 \\
\hline
\end{tabular}

Question 2: Do you still have problems thinking of generalizing words to group related ideas together for better organization?

Yes: $37.7 \%$

No: $62.3 \%$

Question 3: What do you think are the main advantages of the suggested skills of writing a summary? (You may consider more than one)

Table 3 below shows the percentages of respondents indicating the main advantage(s) of the summarizing skills learnt in the course: 
TABLE 3:

MAIN ADVANTAGE(S) OF THE SUGGESTED SKILLS OF WRITING A SUMMARY

\begin{tabular}{ll}
\hline Main Advantage & Percentage \\
\hline The template with headings can show me the structure of a passage, thus helping me to & 65.6 \\
find the main points more easily. & \\
The use of generalizing words helps me to organize individual points, thus improving the & 57.4 \\
organization of a summary. & 26.2 \\
\hline
\end{tabular}

Table 3 shows that more than half of the participants indicated that they had benefited in the following activities: a) finding main points, and b) organizing a piece of summary. However, most of the respondents did not find that the process of generating generalizing words on their own improved their critical thinking. It is possible that their lack of familiarity with pertinent lexicon played a significant part in their limitations; indeed, the participants' lower level proficiency may have invalidated the significance of this finding.

\section{Summary of Questionnaire Findings}

The questionnaire findings indicate that the use of generalizing word -- provided by the present researcher at the initial stage in the process of teaching summarizing and subsequently generated by the participants -- appears to have made summary writing a more manageable task for students possessing low-level English proficiency. Two important teaching aids - first, a template containing generalizing words to show the macro structure of a passage; second, a list of main points that had been paraphrased - had been indicated by an overwhelming majority of participants to be useful. In particular, the participants appeared to believe that they had benefited from the teaching in two regards: a) finding main points more easily, and b) grouping the main points in a more organized manner.

However, about $40 \%$ of the students from the experimental group still found it difficult to think of generalizing words, although more than half of the respondents indicated that they did not have difficulty generating generalizing words. The difficulties of the students having problems generating generalizing words include the following (as indicated in responses to the open-ended questions in the questionnaire):

Not understanding individual sentences,

- Not understanding the main idea of a paragraph,

- Vocabulary problems,

- Not able to come up with ideas.

\section{DISCUSSION AND CONCLUSION}

The slightly higher scores in the three measures (i.e., Paraphrasing Skills, Idea Flow and Total Score) awarded to the experimental group might suggest that, though not significant, the use of generalizing words had helped develop the students' summarizing ability to some extent. There are two possible reasons for the slightly higher scores. First, the score of Idea Flow was awarded largely based on the organization of the ideas presented in a summary. Second, generalizing words are meant to improve the organization of a summary. Given these assumptions, it was possible to assume that the slightly higher scores in Idea Flow might be the result of the use of generalizing words. Similarly, the provision of examples of paraphrased sentences in the six sample summaries were meant to improve students' paraphrasing skills; the award of marks to "Paraphrasing Skills" was based on whether the ideas written in a summary were expressed in students' own words, whether or not the sentences written in the summary were in fact the main points of the passage.

However, because the score differences in these measures were not significant, the claim that the use of generalizing words and the sample paraphrased sentences might have produced positive effects on students' summary writing performance can only be tentative.

The insignificance of the differences in the scores in the three categories (i.e., Idea Flow, Paraphrasing Techniques and Total Score) between the two groups might be due to the ineffectiveness of the generalizing words as a means to improve students' summarizing performance. This speculation seems reasonable, since about $40 \%$ of the participants in the experimental group expressed the concern that they had difficulty generating appropriate generalizing words. Perhaps a pre-requisite to writing a good summary lies in a student's linguistic ability to understand a sentence as well as his/her knowledge of discourse structure. It is highly likely that, if a student cannot make sense of individual sentences, s/he may not be able to generate generalizing words, especially among those students who cannot use effective previewing skills to generate generalizing words.

A further reason for the insignificance of the findings might be that it would take a much longer period of time for learners to improve their summarizing skills. As mentioned earlier, the subjects in this report were only taught summarizing skills for 13.5 hours - that is, from Lesson 4 to Lesson 12 - and only for 1.5 hours in each lesson. In view of this time constraint, future studies could incorporate a substantially longer period of time for teaching summarizing skills.

The finding that the experimental group's score in Content was not higher than that of the control group despite the former's slightly higher score in Idea Flow is worth discussing. The experimental group's lower marks in Content possibly means that generalizing words did not actually help students to find the main points, perhaps because their language ability was so low that they were simply unable to understand individual sentences. However, it is interesting 
to observe that these students, who were weak at reading comprehension, were still able to obtain slightly higher marks in "Idea Flow," a phenomenon that might be due to the fact that they still were able to write a summary in which ideas were logically connected, although those ideas were not the main points, by applying the skills making use of generalizing words.

To conclude, the teaching of generalizing words in the present study has not yielded significant differences in the five examination scores between the control and the experimental groups, although the slightly higher scores in three of them (i.e., Idea Flow, Paraphrasing skills and Total Score) seem to suggest that the usefulness of generalizing words might deserve further investigation. It would be useful to involve students with a high level of English proficiency who have the basic linguistic ability to understand the meaning of individual sentences for future research studies.

\section{Appendix A. Part of the Outline Temple (with Suggested Answers) Produced for the Passage Death: A Discovery APPROACH (TAKEN FROM THE EAP II COURSE BOOK USED BY THE PARTICIPANTS IN THIS STUDY):}

(Students were reminded to paraphrase the words provided in the article when they wrote their summaries.)

\begin{tabular}{|c|c|c|}
\hline Headings & $\begin{array}{l}\text { Corresponding generalizing words } \\
\text { that could be used to introduce a set of } \\
\text { details }\end{array}$ & Specific details \\
\hline \multirow[t]{3}{*}{ WAYS TO VIEW DEATH } & - Justification for the course & $\begin{array}{l}\text { - Reason 1: Death is not discussed } \\
\text { openly in Chinese communities. } \\
\text { - Reason 2: We are confronted by images } \\
\text { of death, often with very violent and } \\
\text { graphic images }\end{array}$ \\
\hline & - Aim of the course & $\begin{array}{l}\text { - To inspire students to examine } \\
\text { fundamental questions about death }\end{array}$ \\
\hline & - Feature of the course & • Multidisciplinary \\
\hline INTER-DISCIPLINARY INPUT & - First perspective: social & $\begin{array}{l}\text { - Department of Applied Social Studies } \\
\text { - We need to include a study of ethics, } \\
\text { religion and humanism when talking } \\
\text { about death. Subjects like euthanasia } \\
\text { and living wills are becoming more } \\
\text { important in contemporary societies. }\end{array}$ \\
\hline
\end{tabular}

\section{Questionnaire}

\section{RESEARCH QUESTIONMAIRE SUMMARY WRITING}

Dear EAP Part II Students,

You are cordially invited to participate in a research study investigating the effectiveness of the summarizing skills I taught you in this course. Hopefully, the findings can contribute to the teaching of summary in the future. Students' responses elicited in the questionnaire will be analyzed collectively and anonymously. No individuals will be identified in the report of findings. I would be happy to share the findings with you when they are ready upon your request.

Read the questions below and indicate your opinion by circling the appropriate number: 
1. During the experience of learning to write a summary, I have become more aware that:

a) It is important to preview a passage to know the general ideas;

b) I should find out the main idea of each paragraph;

c) A main idea is a statement including some specific information rather than merely general ideas stating what the paragraph is about.

d) Summary writing is primarily a process of selecting and weighing the importance of ideas based on the word limit;

e) An introductory sentence (i.e., one specifying the author, the publication year and the focus of a passage) can improve the organization of the summary;

f) Generalizing words (i.e., words performing the function of headings) can improve the organization of a summary.

2. The process of learning to a write a summary helped me to improve my ability:

a) To preview a passage;

b) To find the main points of a passage;

c) To write an effective introductory sentence;

d) To use generalizing words to organize various points;

e) To use various language skills to cut words to meet the word limit.

\begin{tabular}{ccccc}
$\mathbf{1}=$ Totally disagree & $3=$ Neutral & 5=Totally agree & \\
\hline \hline 1 & 2 & 3 & 4 & 5 \\
1 & 2 & 3 & 4 & 5 \\
1 & 2 & 3 & 4 & 5 \\
1 & 2 & 3 & 4 & 5 \\
1 & 2 & 3 & 4 & 5 \\
1 & 2 & 3 & 4 & 5
\end{tabular}

1=Totally disagree $3=$ Neutral $5=$ Totally agree

\begin{tabular}{lllll}
\hline \hline 1 & 2 & 3 & 4 & 5 \\
1 & 2 & 3 & 4 & 5 \\
1 & 2 & 3 & 4 & 5 \\
1 & 2 & 3 & 4 & 5 \\
1 & 2 & 3 & 4 & 5
\end{tabular}

3. The suggested method of writing a well-organized summary

a) Do you find the templates (e.g., blank tables with headings supplied) I provided to you useful in making the macro structure of the passages clear to you?

$\square$ Yes. The templates are useful.

$\square$ No. The templates are not useful.

$\square$ Other (please specify):

b) Do you think that you have benefited in the long term by seeing the list of main points provided by me after you have attempted to find the main points yourself?

$\square$ Yes.

$\square$ No.

$\square$ Other (please specify):

c) Will you consider using the steps* taught in this class for you future summary writing?

*Previewing $\rightarrow$ find the main idea of each paragraph $\rightarrow$ determine which main ideas to keep for the summary based on the word limit $\rightarrow$ think of

generalizing words to group ideas for better idea flow $\rightarrow$ cut unnecessary words by working on sentence structures.

$\square$ Yes.

$\square$ No.

$\square$ Other (please specify):

4. Do you still have problems thinking of generalizing words to group related ideas for better organization?

$\square$ Yes. What are your current major problems in generating generalizing words?

$\square$ No. I don't think I have problems generating generalizing words.

5. What do you think is the main advantage of the suggested skills of writing a summary? (You may choose more than one answer.)

a) The template with headings can show me the structure of a passage, thus helping me to find the main point more easily;

b) The use of generalizing words helps me to organize individual points, thus improving the organization of a summary;

c) Having to think of generalizing words improves my critical thinking;

d) Others:

e) I don't find the above skills useful. Please specify reason(s):

THANK YOU!

The following personal information will help me interpret the findings from this study. I would be grateful if you could complete this part of the questionnaire as well.

Gender: Male

Date of Birth:

(Month)

Your first language:

If you speak Chinese as your first language, please specify the variety of Chinese you speak (e.g., Cantonese, Hakka, Mandarin):

Major/program:

City where you received your secondary education:

Grade in the Use of English in $\square$ HKDSE:

Year obtaining the exam results:

Name(s) of other English proficiency test(s) taken (E.g. IELTS):

Exam results:

Year obtaining the exam results:

THANK YOU! 


\section{Appendix C. A Sample Summary of the Passage DeATH: A Discovery APPROACH}

This article introduces a GE course aiming to encourage CityU students to examine death from three perspectives: social, scientific, and legal - featuring the collaboration of three departments. The justification for such a course is that talking about death is a social taboo, but youngsters are often bombarded the graphic images of death in daily life. The first perspective concerns morality, humanism and religions; the second examines the natural life cycle of cells, possibly hinting at ways to treat cancer and making humans immortal; and the third examines legal matters in handling suicide, and end-of-life issues. While addressing the issue of youngsters being a sensitive group, positive thinking towards death constitutes the underlying principles of various activities held in the course. (120 words)

\section{Appendix D. Part of the Teaching Materials in the Student Course BookLet for Teaching SuMmarizing SKILLS}

Source: UNIT 4, EAP II Student Booklet 2014-15

Task 5

An Introduction to summaries

Summarising is a skill that is extremely useful in your university studies. Summarising involves finding the main ideas in a text and presenting them in your own words.

To write an effective summary, you need to:

1. read the text well. This means you should find the main ideas, look at genre, text structure. You should also pay attention to cohesive features (general nouns, lexical chains and semantic sets, general noun, referencing...), the author's stance/opinion... The questions in task 4 have helped you do this with the text 'Learning about life'

2. write a good text in your own words that accurately reflects the original and flows well (is coherent): use hypernyms, paraphrasing techniques (see unit 3), reflect the genre and text structure, theme patterns...

\section{Task 5A}

Discuss the following questions in groups. Write your answers in the space provided.

\section{A. What makes a good summary}

Brainstorm the elements of a good summary

\section{B. Steps taken when writing a summary}

\section{What are the features of a good summary?}

- It should be about $10 \%-15 \%$ of the original in length.

- It should start with an opening sentence which introduces the topic. It should focus exclusively on main points, omitting details, examples, supporting quotations, description, etc.

- It should include ALL the main points of the original.

- If the original is discussing an issue, it should clearly show the author's opinion.

- It should NOT include things that were not in the original, like your own ideas about the topic.

- It should be IN YOUR OWN WORDS.

- It should be clear to a reader who has not read the original.

\section{What are the steps in writing a summary?}

1. Read the text. 
2. Identify the genre then look for organizational patterns.

3. Reread the text, underlining the main ideas/key points and crossing out less important details, examples, etc. Pay particular attention to the introduction, topic sentences and the conclusion.

4. Take notes of all the main ideas/key points in the margin or on a separate piece of paper. Do this in your own words

5. Begin with an opening sentence which introduces the topic. Remember the reader of the summary may not have read the original text.

6. Mention the important facts in a logical / chronological order. This may not be the same as in the original text.

7. As you write, do not copy the original. These strategies (which you have seen in Unit 3) can help you:

- Using synonyms

- Changing the form of individual words, e.g. verbs to nouns

- Using an alternative sentence structure

- Using the passive / changing passive to active forms

- Changing single nouns to plural nouns and vice versa

- Adding your own cohesive devices to show the relationships between the ideas

If possible, try not to 'stick' to the original when writing your summary. Imagine you are re-telling the text to a friend. Get the ideas in your head and then try to write the summary without referring to the original. This skill gets easier with more practice!

8. Check that your summary reflects the original.

\section{Recognizing genre when summarizing}

Many texts are examples of one of the following genres. If you can recognize it and its associated organizational pattern, it may make your task easier.

- Description or narrative

- Cause and effect

- Comparison and contrast

- Classification and division

Task 6

Note: The features of a good summary above are relevant for this course but might not be the same in other courses or for other types of summaries.

A summary is also a type of citation that is especially useful in longer papers. When including a summary in an essay, you need to use the same citation techniques you would use for a direct quote or a paraphrase: name of the author and date should be present.

\section{EAP 2 final exam requirements:}

In EAP part 2, you are assessed on your ability to extract the relevant ideas of a text (according to the guiding question gi ven), to summarise them in your own words while staying true to the original meaning. The EAP Final exam summary is not used as a citation so you are NOT required to write the name of the author or the date (as you would when using a summary in an essay). You are required to start your summary with an opening sentence that encapsulates the text's main message.

In the exam, the summary word count will be specified and should be between 10 and $15 \%$ of the original.

Constructing a summary

In small groups, write a summary of the text. "Learning about Life". Look at the guiding question below to help you select relevant main ideas from the text:

You are writing a report about interdisciplinary GE courses at City University. Summarise the information about the course "Death: A

Discovery Approach" in the text "Learning about Life" to include in your report.

- Start with an overall opening sentence

- Rephrase the main points and write them into ONE coherent paragraph

- Check that you are including only main points

- Make sure you keep within the word limit (10 to 15\% of the original)

- Are all the ideas relevant to the guiding question?

- Are you reflecting the author's ideas/opinions truthfully?

- Are you using your own words (as far as possible)?

- Is your summary perfectly clear to a reader who has not seen the original? 


\section{REFERENCES}

[1] Alfassi, M. (2004). Reading to learn: Effects off combined strategy instruction on high school graduate students. Journal of Educational Research, 97, 171-184.

[2] Chen Y. S. \& Su, S. W. (2012). A genre-based approach to teaching EFL summary writing. ELT Journal 66 (2), $184-192$.

[3] Chou, M. H. (2012). Implementing keyword and question generation approaches in teaching EFL summary writing. English Language Teaching 5 (12). 36-41.

[4] De Fina, A. A. (1992). Portfolio assessment: Getting started. New York: Scholastic Inc.

[5] Ercan, G. \& Cicekli, I. (2007). Using lexical chains for keyword extraction. Information Processing \& Management, 43, 17051714.

[6] Esmaeili, H. (2002). Integrating reading and writing tasks and ESL students' reading and writing performance in an English language test. Canadian Modern Language Review, 58, 599-622.

[7] Fischer, C. (2003). Revisiting the reader's rudder: A comprehension strategy. Journal of Adolescent \& Adult Literacy, 47, 248256.

[8] Friend, R. (2001). Effects of strategy instruction in summarization of college students. Contemporary Educational Psychology, 26(1), 3-24.

[9] Fritz, C. O., Morris, P. E., Acton, M., Voelkel, A. R., Etkind, R. (2006). Comparing and combining retrieval practice and the keyword mnemonic for the foreign language learning. Applied Cognitive Psychology, 21 (4), 499-526.

[10] Halliday, M. A. K., \& Matthiessen, C. M. I. M. (1999). Construing experience through meanings: A language-based approach to cognition. London: Cassell.

[11] Hood, S. (2008). Summary writing in academic contexts: Implicating meaning in processes of change. Linguistics and Education, 19, 351-365.

[12] Kintsch, W. (1998). Comprehension: A paradigm of cognition. Cambridge, UK: Cambridge University Press.

[13] Plakans, L. (2009). The role of reading strategies in integrating L2 writing task. Journal of English for Academic Purposes, 8 , 252-266.

[14] Sagarra, N., \& Alba, M. (2006). The key is in the keyword: L2 vocabulary learning methods with beginning learners of Spanish. The Modern Language Journal, 90(2), 228-234.

[15] Silver, T., \& Matsuda, P. K. (2002). Writing. In N. Schmitt (Ed.), An introduction to applied linguistics (pp. 251-266). London: Arnold.

[16] Stein, N. L. \& Glenn, C. G. (1979). An analysis of story comprehension in elementary school children. In R. Freedle (ed.) Multidisciplinary Approaches to Discourse Comprehension. Hillsdale, NJ: Ablex.

[17] Wang, A. Y., Thomas, M. H. \& Quellette, J. A. (1992). Keyword mnemonic and retention of second language vocabulary words. Journal of Educational Psychology, 84(4), 520-528.

[18] Wu, P. H., Hwang, G. J., Milrad, M., Ke, H. R., \& Huang, Y. M. (2012). An innovative concept map approach for improving students' learning performance with an instant feedback mechanism. British Journal of Educational Technology, 42(2), 217232.

[19] Yang, Y. F. (2014). Preparing language teachers for blended teaching of summary writing. Computer Assisted Language Learning, 27(3), 185-206.

[20] Yang, Y. F. (2015). Automatic scaffolding and measurement of concept mapping for EFL Students to write summaries. Educational Technology \& Society 18(4), 273-286.

[21] Yang, Y. F. (2016). Transforming and constructing academic knowledge through online peer feedback in summary writing. Computer Assisted Language Learning, 29(4), 683-702.

Fiona Kwai-peng SIU received her doctorate in Applied Linguistics from Macquarie University, Sydney, in 2009. She is currently an EFL teacher in the English Language Centre (ELC), City University of Hong Kong. Her research interests include pragmatics (in particular, politeness strategies in making requests) and academic writing.

Dr. SIU can be contacted by email at fiona.siu@ cityu.edu.hk. 